Supplement of Biogeosciences, 16, 4357-4375, 2019

https://doi.org/10.5194/bg-16-4357-2019-supplement

(c) Author(s) 2019. This work is distributed under

the Creative Commons Attribution 4.0 License.

(c) (1)

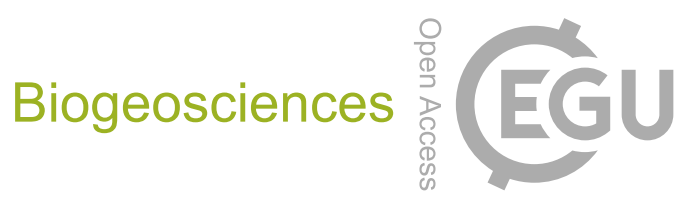

Supplement of

\title{
Stand age and species composition effects on surface albedo in a mixed- wood boreal forest
}

Mohammad Abdul Halim et al.

Correspondence to: Mohammad Abdul Halim (abdul.halim@mail.utoronto.ca)

The copyright of individual parts of the supplement might differ from the CC BY 4.0 License. 


\section{Field comparisons of silicon-based pyranometers and thermopile pyranometers for land surface albedo measurements}

\section{S1. Background}

In "Stand age and species composition effects on surface albedo in a mixedwood boreal forest" we use silicon (Si) photocellbased pyranometers (Hobo: Onset Computer, Massachusetts, USA) (spectral range: 300-1100 nm; measurement range: 0$1280 \mathrm{Wm}^{-2}$ ) to measure albedo of mixedwood boreal stands in post-fire and post-harvest chronosequences. Most prior published albedo measurements used thermopile pyranometers with a broader spectral range ( $\sim 300-2800 \mathrm{~nm})$. Although the narrower spectral range of Si-based pyranometers might result in lower estimates of total energy flux, potential biases in

albedo estimates are less clear, and direct performance comparisons of both sensor types are very few (Dirmhirn, 1968; François et al., 2002; Stroeve et al., 2005). Direct field comparisons of the Si-based pyranometers with thermopile pyranometers are not available. In the study, we also used published albedo values (secondary data) from recent post-fire sites of similar stand structure and composition and climate, and data from the old (> 70 years) boreal jack pine (Pinus banksiana) stands to model trends in albedo change with changing stand age, structure, and composition. Studies providing secondary albedo data used thermopile-based pyranometers (Kipp and Zonen CNR1 and Eppley precision spectral pyranometer).

Here we present results of a supplementary calibration study conducted over nine days under variable sky conditions (\% cloudiness) and ground cover (snow cover) conditions, to assess the relative performance of Si-based Hobo pyranometers in comparison to thermopile pyranometers.

\section{S2. Materials and Methods}

We deployed two pairs (one pair upfacing and one pair downfacing) of Si-based Hobo pyranometers at a similar height ( $\sim 2$ $\mathrm{m})$ to a CNR1 net radiometer (Kipp and Zonen, The Netherlands) on $21^{\text {st }}$ February to $3^{\text {rd }}$ March 2019 at the Elora Research Station, Guelph, Ontario $\left(43.64^{\circ} \mathrm{N}, 80.41^{\circ} \mathrm{W}\right.$ ) (Photo S1). Si-based pyranometers were set to measure solar radiation at 10min intervals (same intervals used in the main study) and the CNR1 logged measurements at 30-min intervals. Out of the 11day measurements, we excluded measurements of two snowy days - the same filtering scheme used in the main study. Over the selected nine days, sky cloudiness varied from $20-100 \%$ and albedo varied from $0.29-0.88$ (because of varying snow cover conditions). Weather data was collected from the closest (within a $\mathrm{km}$ ) Environment Canada weather station (Environment Canada, 2019). This Elora site is a post-harvest cornfield where some corn stalks are protruding through the snow cover, closely analogous to our recent post-harvest sites. We specifically chose an open site to test the performance of Si pyranometers in high snow-covered ground conditions, since studies have reported the greatest divergence in measurements between Si-based and thermopile pyranometers under conditions of high snow reflectivity (Dirmhirn, 1968; Stroeve et al., 2005).

One of the two pairs of (up/down-facing) Si pyranometers were old (used in the field for about a year) and the other pair was new (never used in the field); this enabled an evaluation for possible performance degradation due to field usage. Since CNR1 is a net radiometer, for this comparison, we only used data from the up- and down-facing CM3 modules (spectral range 305$2800 \mathrm{~nm}$, measurement range: $0-1000 \mathrm{Wm}^{-2}$ ). The CNR1 net radiometer unit used in this study was factory calibrated approximately two months prior to the measurements. 
pyranometers were compared to the hourly average of CNR1 measurements. The daily total incoming $\left(I_{d}\right) /$ reflected $\left(R_{d}\right)$ solar radiations for both pairs of Si-based pyranometers were calculated and their averages were compared with the total $I_{d} / R_{h}$ of CNR1. Albedo $(\alpha)$ for each pyranometer was calculated as the ratio of total $R_{d}$ and total $I_{d}$ radiation. The daily average $\alpha$ from the two pairs of Si-based pyranometers was compared to the $\alpha$ value from the CNR1 pyranometer. For performance comparisons, simple linear regression models were used, testing the hypotheses that the intercept of linear regression was not different from 0 and the slope not different from 1 (using the linearHypothesis() function of the R package "car" (Fox and Weisberg, 2011)). All analyses were conducted using the R statistical platform (The R Core Team, 2019). Graphs were created using the R-package 'ggplot2' (Wickham, 2016).

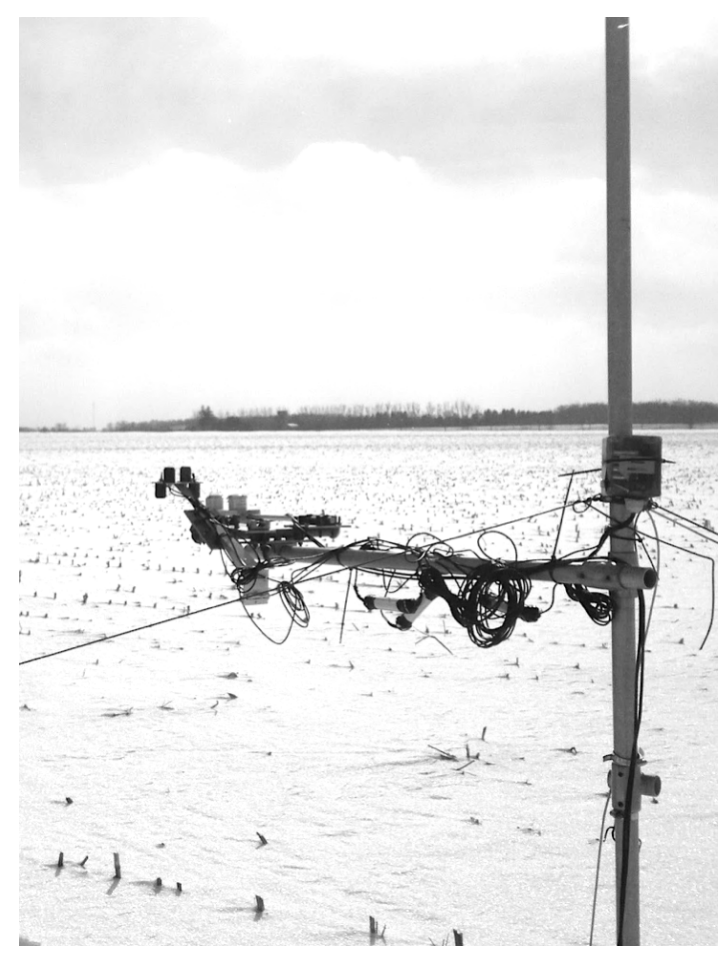

Photo S1: Silicon-based and CNR1 pyranometers measuring albedo at the Elora Research Station, Guelph, Ontario, Canada (Photo Credit: Shannon Brown, Postdoctoral Research Associate, School of Environmental Science, University of Guelph).

\section{S3. Results and Discussions}

Results from the simple linear regression of $I_{h}$ measured by CNR1 and Si-based pyranometers indicated a very close match

between measurements $\left(\mathrm{R}^{2}=0.985\right.$, Residual Standard Error $\left.[\mathrm{RSE}]=28.05, \mathrm{p}<0.01\right)$ (Fig. S1a). The regression intercept $(-1.36)$ was not significantly different from $0(\mathrm{p}>0.05)$; as expected the slope (1.23) was significantly different from $1(\mathrm{p}<$ 

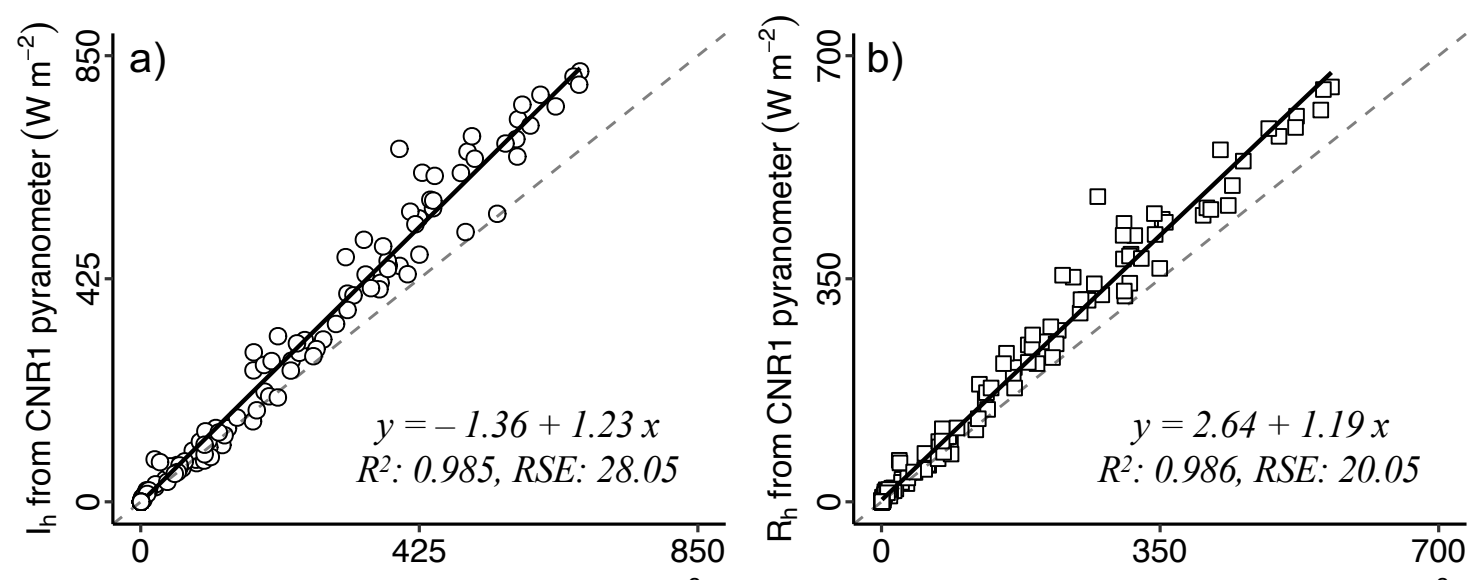

$\mathrm{I}_{\mathrm{h}}$ from $\mathrm{Si}$ - based pyranometers $\left(\mathrm{W} \mathrm{m}^{-2}\right)$

$\mathrm{R}_{\mathrm{h}}$ from $\mathrm{Si}$ - based pyranometers $\left(\mathrm{W} \mathrm{m}^{-2}\right)$
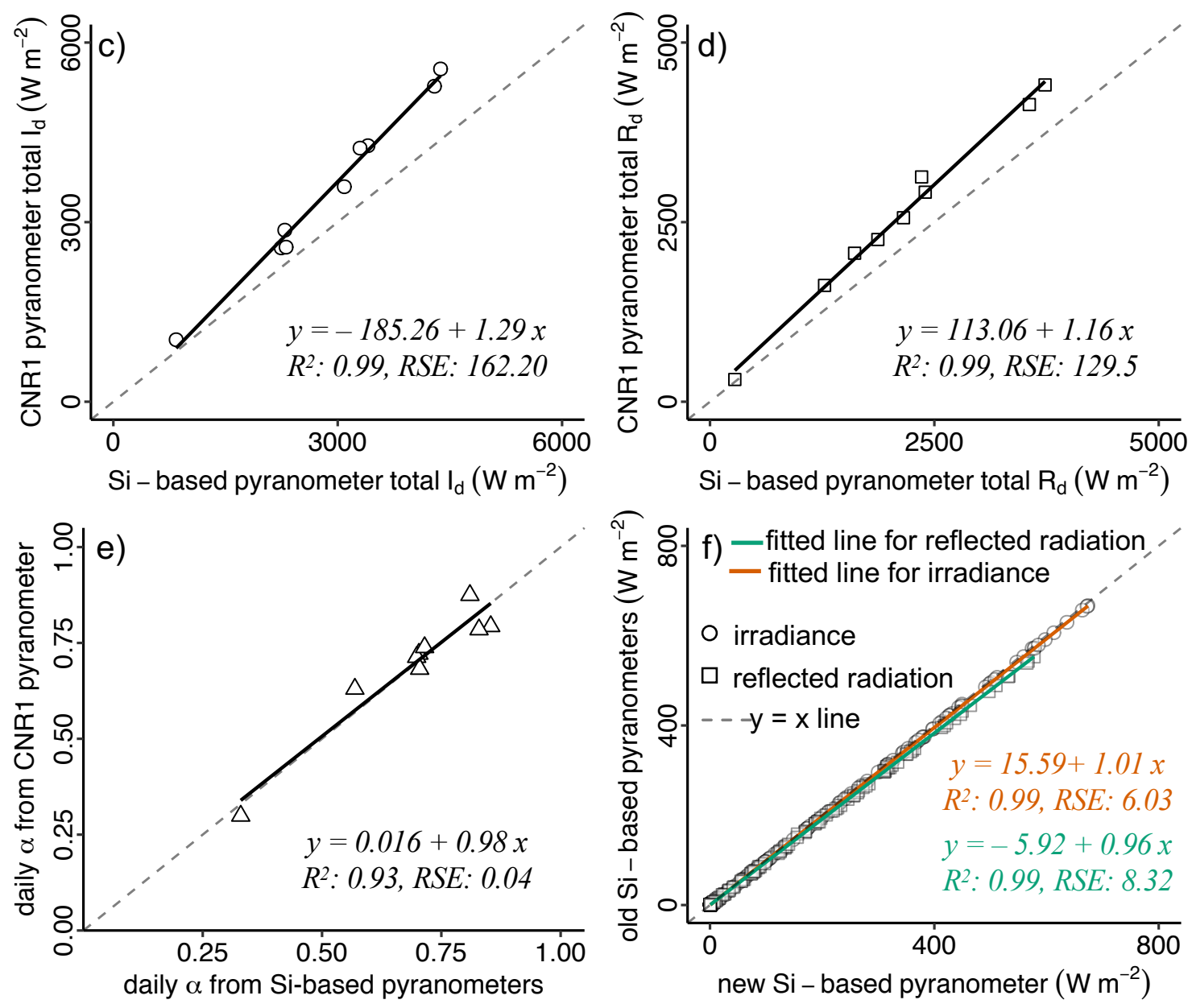

Figure S1. Field comparisons of Si pyranometers (300-1100 nm) with thermopile pyranometers (305-2800 nm) under different sky and ground conditions over nine days. a) comparison of measured hourly irradiance $\left(\mathrm{I}_{\mathrm{h}}\right)$. b) comparison measured hourly reflected radiation $\left(R_{h}\right)$. c) comparison of measured daily total irradiance $\left(I_{d}\right)$. d) comparison of measured daily total reflected radiance $\left(R_{d}\right)$. e) comparison of measured daily albedo $(\alpha)$. f) comparison of old vs. new Si-based pyranometers measurements of hourly irradiance and reflected radiation. RSE indicates Residual Standard Error.

0.01), reflecting additional measured energy flux at wavelengths $>1100 \mathrm{~nm}$. A similar strong linear relationship $\left(\mathrm{R}^{2}=0.986\right.$, 
RSE $=20.05, \mathrm{p}<0.01)$ was also observed for $R_{h}$ measured by CNR1 and Si-based pyranometers (Fig. S1b). The regression intercept (2.64) was not significantly different from $0(\mathrm{p}>0.05)$ and the slope (1.19) was significantly different from $1(\mathrm{p}<$ 0.01). The correspondence between pyranometers was higher for $R_{h}$ than it was for $I_{h}$ as indicated by higher $\mathrm{R}^{2}$ and lower RSE. The correlation between measurements from the two types of pyranometers was even stronger when considered over a 24-hour period. For total $I_{d}$ the regression intercept was not significantly different from 0 ( $\left.p>0.05\right)$ and the slope (1.29) was not significantly different from $1(\mathrm{p}=0.08)\left(\mathrm{R}^{2}=0.99, \mathrm{RSE}=162.20, \mathrm{p}<0.01\right)$ (Fig. S1c). For total $R_{d}$ the regression intercept was also not significantly different from $0(p>0.05)$ and the slope $(1.16)$ was not significantly different from $1(p=0.07)\left(R^{2}\right.$ $=0.99, \operatorname{RSE}=129.5, \mathrm{p}<0.01)($ Fig. S1d).

Results from the simple linear regression for $I_{h}$ and $R_{h}$ measurements from the old and new Si-based pyranometers indicated exceptionally close correspondence $\left(\mathrm{R}^{2}=0.99, \mathrm{p}<0.01\right)$ (Fig. S2f). For $I_{h}$ the regression intercept (15.59) was significantly different from $0(\mathrm{p}=0.03)$ and the slope (1.01) was not significantly different from 1 ( $\mathrm{p}>0.05)$. For $R_{h}$ the regression intercept $(-5.92)$ was however not different from $0(p>0.05)$ and the slope $(0.96)$ not different from $1(p=0.1)$.

Figure S1e indicates close agreement in daily albedo measurement between the CNR1 and Si-based $\left(\mathrm{R}^{2}=0.93, \mathrm{RSE}=0.04\right.$, $\mathrm{p}<0.01)$. The regression intercept $(0.016)$ of this relationship was not significantly different from $0(\mathrm{p}>0.05)$ and the slope $(0.98)$ was not significantly different from $1(\mathrm{p}>0.05)$. The daily albedo difference between the CNR1 and Si-based pyranometers ranged from -0.0601 to 0.064 , which was well within the previously reported acceptable $(\sim 5-7 \%)$ error range for class one pyranometers (Myers, 2010; Stroeve et al., 2005). Over the nine-day measurement period, the mean absolute difference in daily albedo was 0.037 ( \pm 0.014$)$, and the mean difference in average daily albedo was negligible $(0.0028 \pm 0.031)$. We did not find any detectable pattern in deviations between sensor types with increased/decreased cloud cover and ground snow cover. Since the difference in mean daily albedo values is negligible and the regression slope and intercept are not statistically different from 1 and 0, respectively, we conclude that albedo measurements of CNR1 and Si-based pyranometers used are closely comparable, and thus there is no need to perform any corrections on Si-based pyranometer measurements.

\section{S4. References}

Dirmhirn, I.: On the use of silicon cells in meteorological radiation studies, Journal of Applied Meteorology, 7(4), 702-707, 1968.

Environment Canada: Historical climate data, [online] Available from: http://climate.weather.gc.ca/historical_data/search_historic_data_e.html (Accessed 4 March 2019), 2019.

95

Fox, J. and Weisberg, S.: An $\{\mathrm{R}\}$ Companion to Applied Regression, 2nd ed., Sage, Thousands Oaks, CA. [online] Available from: http://socserv.socsci.mcmaster.ca/jfox/Books/Companion, 2011.

François, C., Ottlé, C., Olioso, A., Prévot, L., Bruguier, N. and Ducros, Y.: Conversion of 400-1100 nm vegetation albedo measurements into total shortwave broadband albedo using a canopy radiative transfer model, Agronomie, 22(6), 611-618, doi:10.1051/agro:2002033, 2002.

Myers, D. R.: Comparison of direct normal irradiance derived from silicon and thermopile global hemispherical radiation detectors, edited by N. G. Dhere, J. H. Wohlgemuth, and K. Lynn, p. 77730G, San Diego, California., 2010. 
Stroeve, J., Box, J. E., Gao, F., Liang, S., Nolin, A. and Schaaf, C.: Accuracy assessment of the MODIS 16-day albedo product for snow: comparisons with Greenland in situ measurements, Remote Sensing of Environment, 94(1), 46-60, doi:10.1016/j.rse.2004.09.001, 2005.

110 The R Core Team: R: A language and environment for statistical computing, R, R Foundation for Statistical Computing, Vienna, Austria., 2019.

Wickham, H.: ggplot2: Elegant Graphics for Data Analysis, R, Springer-Verlag, New York. [online] Available from: http://ggplot2.org, 2016.

115

120

125 


\section{Supplementary Tables}

Supplementary Table 1: Regression model coefficients and fit statistics for albedo as a function of stand attributes (without secondary data) in different seasons in the boreal forest

\begin{tabular}{|c|c|c|c|c|c|c|c|c|}
\hline \multirow{3}{*}{ 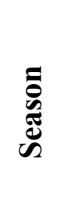 } & \multicolumn{4}{|c|}{ Post-harvest stands } & \multicolumn{4}{|c|}{ Post-fire stands } \\
\hline & \multicolumn{2}{|c|}{ Parameter Estimates } & \multicolumn{2}{|c|}{ Model Fit } & \multicolumn{2}{|c|}{ Parameter Estimates } & \multicolumn{2}{|c|}{ Model Fit } \\
\hline & Coefficient & Estimate & $\triangle A I C$ & Adj. $R^{2}$ & Coefficient & Estimate & $\triangle A I C$ & Adj. $R^{2}$ \\
\hline \multirow{6}{*}{$\stackrel{\vec{\oplus}}{\stackrel{.}{!}}$} & Intercept & -49.53 & \multirow{6}{*}{-560.7} & \multirow{6}{*}{0.99} & \multirow{6}{*}{$\begin{array}{l}\text { Intercept } \\
\text { SA } \\
\text { PDPS } \\
\text { SA:PDBS }\end{array}$} & & \multirow{6}{*}{-18.2} & \multirow{6}{*}{0.84} \\
\hline & SA & 11.99 & & & & 0.056 & & \\
\hline & PDBS & 0.926 & & & & -0.111 & & \\
\hline & $\mathrm{CH}$ & 1.728 & & & & -0.022 & & \\
\hline & $\mathrm{SA}: \mathrm{CH}$ & -0.659 & & & & 0.002 & & \\
\hline & SA:PDBS & -0.228 & & & & & & \\
\hline \multirow{5}{*}{$\begin{array}{l}\text { : } \\
\text { : } \\
\text { की }\end{array}$} & Intercept & -7.195 & & & \multirow{5}{*}{$\begin{array}{l}\text { Intercept } \\
\text { SA } \\
\text { PDBS }\end{array}$} & & \multirow{5}{*}{-18.8} & \multirow{5}{*}{0.92} \\
\hline & SA & 1.298 & & & & -1.747 & & \\
\hline & PDBS & 0.116 & -495.4 & 0.99 & & 0.016 & & \\
\hline & $\mathrm{CH}$ & -1.264 & & & & 0.002 & & \\
\hline & SA:PDBS & -0.024 & & & & & & \\
\hline \multirow{7}{*}{$\begin{array}{l}\bar{\Xi} \\
\text { 音 } \\
\text { हn }\end{array}$} & Intercept & -3.987 & & & \multirow{7}{*}{$\begin{array}{l}\text { Intercept } \\
\text { SA } \\
\text { PDBS } \\
\text { CH } \\
\text { SA:PDBS }\end{array}$} & & \multirow{7}{*}{-289.8} & \multirow{7}{*}{0.97} \\
\hline & SA & 0.176 & & & & 6.591 & & \\
\hline & PDBS & 0.017 & & & & -1.473 & & \\
\hline & GVC & 0.074 & -571.3 & 0.99 & & -0.142 & & \\
\hline & SA:GVC & -0.004 & & & & 2.379 & & \\
\hline & PDBS:GVC & -0.001 & & & & 0.158 & & \\
\hline & SA:PDBS & $7.4 e-05$ & & & & & & \\
\hline \multirow{8}{*}{$\overline{\bar{\sigma}}$} & Intercept & 0.398 & \multirow{7}{*}{-6.1} & \multirow{7}{*}{0.94} & \multirow{2}{*}{\multicolumn{2}{|c|}{$\frac{4.5}{6.87} e^{\left(-\frac{S A-13.2}{6.87}-e^{-\frac{S A-13.2}{6.87}}\right)}$}} & \multirow{2}{*}{-3.1} & \multirow{2}{*}{$0.045^{1}$} \\
\hline & SA & 0.013 & & & & & & \\
\hline & $\mathrm{CH}$ & -0.182 & & & \multirow{6}{*}{\multicolumn{2}{|c|}{$0.99 e^{0.013 P D B S}$}} & \multirow{6}{*}{-25.4} & \multirow{6}{*}{$0.008^{1}$} \\
\hline & GVC & -0.007 & & & & & & \\
\hline & $\mathrm{SA}: \mathrm{CH}$ & 0.007 & & & & & & \\
\hline & $\mathrm{CH}: \mathrm{GVC}$ & 0.005 & & & & & & \\
\hline & SA:CH:GVC & -0.0002 & & & & & & \\
\hline & $\frac{28.86}{45.39} e^{(-}$ & $\left.-\frac{P D B S-67.62}{45.39}\right)$ & -0.9 & $0.049^{1}$ & & & & \\
\hline
\end{tabular}

Notes: SA, PDBS, CH, and GVC indicate stand age (year), proportion of deciduous broadleaf species (\%), canopy height (m), and ground vegetation cover (\%), respectively. Parameter estimates for GLMs in bold and regular fonts indicate statistical significance at $1 \%$ and $5 \%$ level, respectively. For fall nonlinear regression models, 28.86 and 45.39 coefficients of post-harvest stands were significant at 5\% level and the rest is significant at 1\% level. ${ }^{1}$ indicates residual stand error of the nonlinear regression model. $\triangle \mathrm{AIC}=\mathrm{AIC}$ of the best-fit model $-\mathrm{AIC}$ of the corresponding null model. The goodness-of-fit of these models were compared against the corresponding null models (using deviance) and were found to be significantly better than the corresponding null models. 


\section{Other Supplementary Figures}
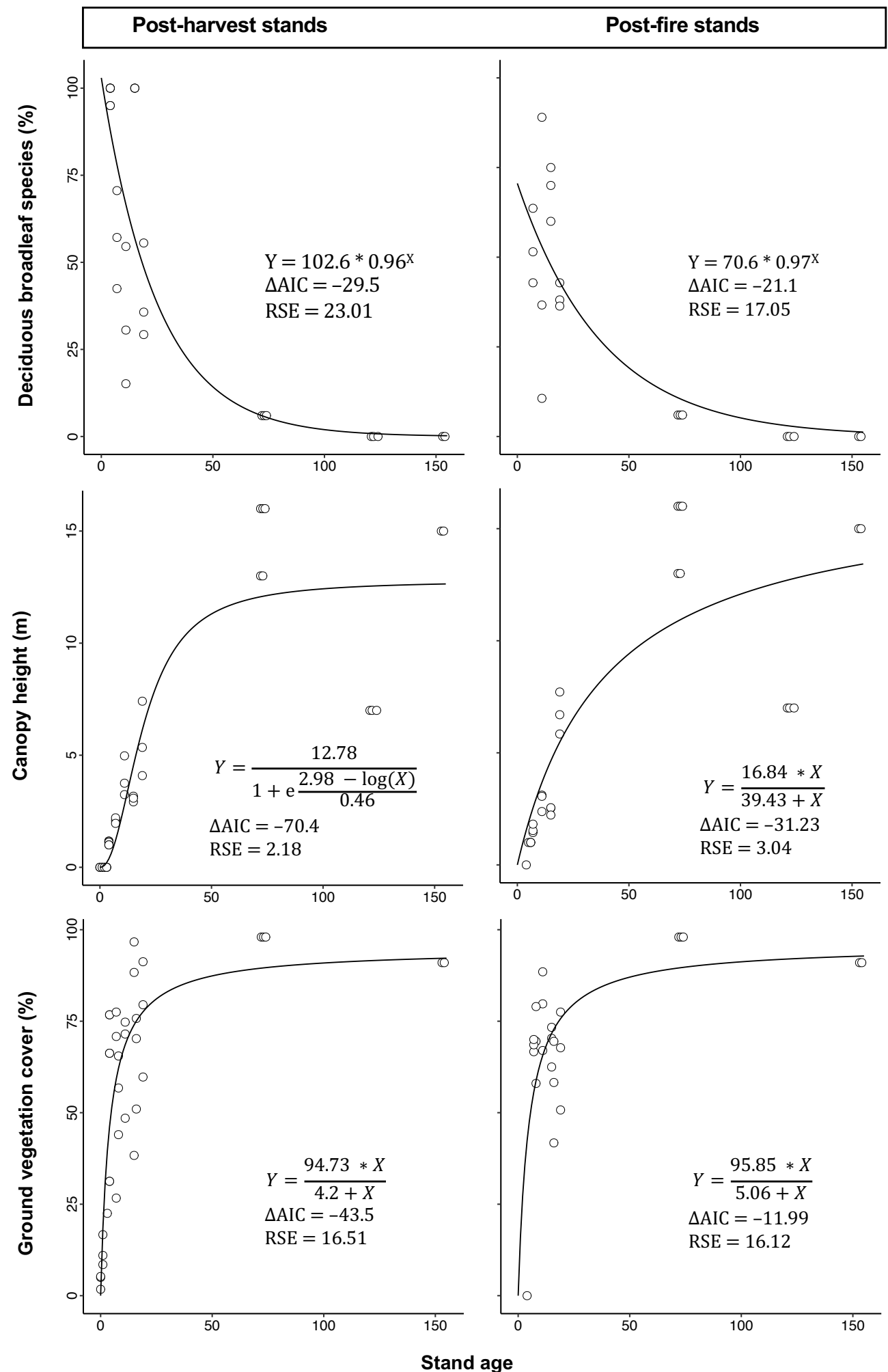

Supplementary Figure 2. Relationships between stand age and stand structural properties in the winter season. Best-fit models were selected using an AIC-based algorithm from a set of candidate models. Estimated parameters of all models are significant at $5 \%$ level. $\Delta$ AIC $=\mathrm{AIC}$ of the best-fit model $-\mathrm{AIC}$ of the corresponding null model. RSE $=$ Residual Standard Error of the best-fit model. 


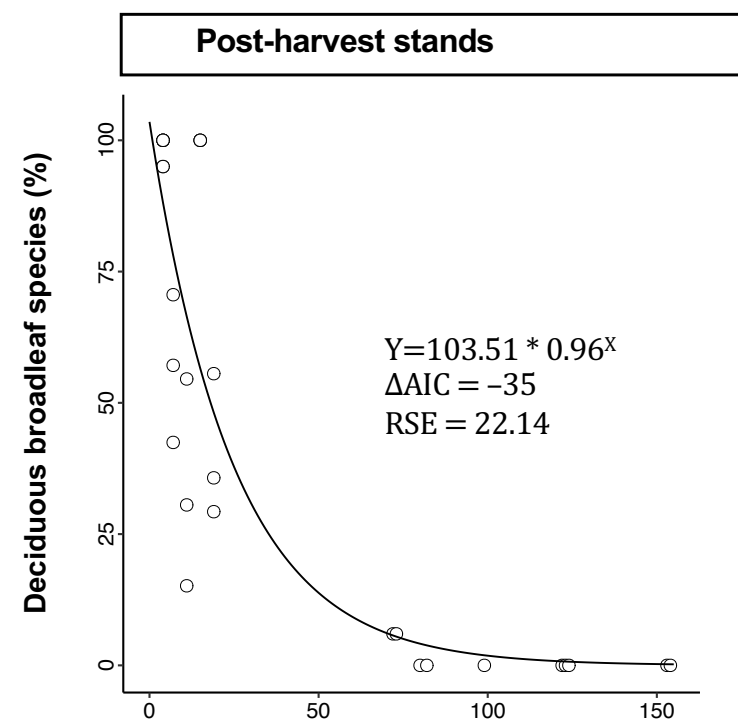

Post-fire stands
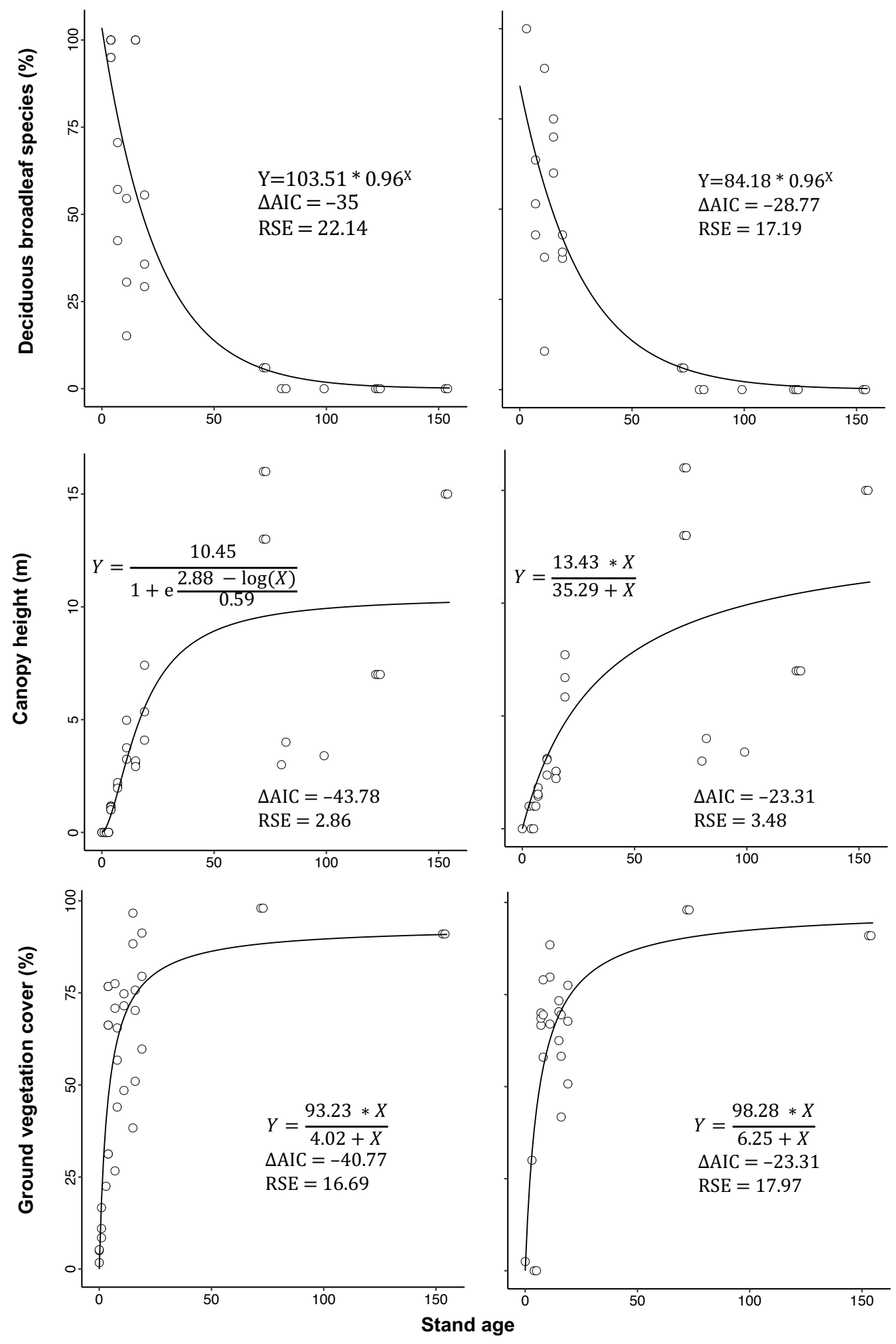

155 Supplementary Figure 3. Relationships between stand age and stand structural properties in the summer season. Best-fit models were chosen using an AIC-based algorithm from a set of candidate models. Estimated parameters of all models are significant at $5 \%$ level. $\Delta$ AIC $=\mathrm{AIC}$ of the best-fit model - AIC of the corresponding null model. RSE $=$ Residual Standard Error of the best-fit model. 


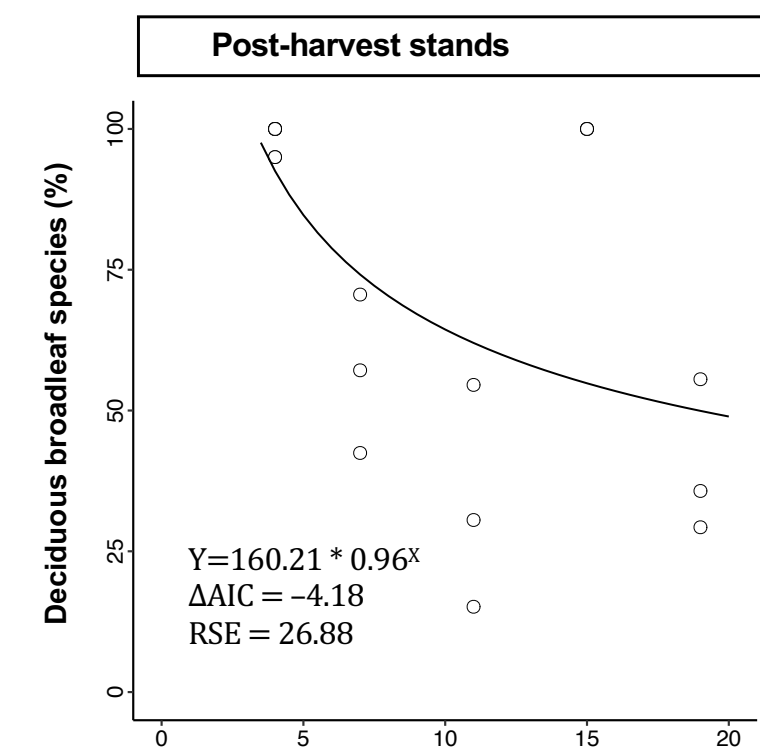

Post-fire stands
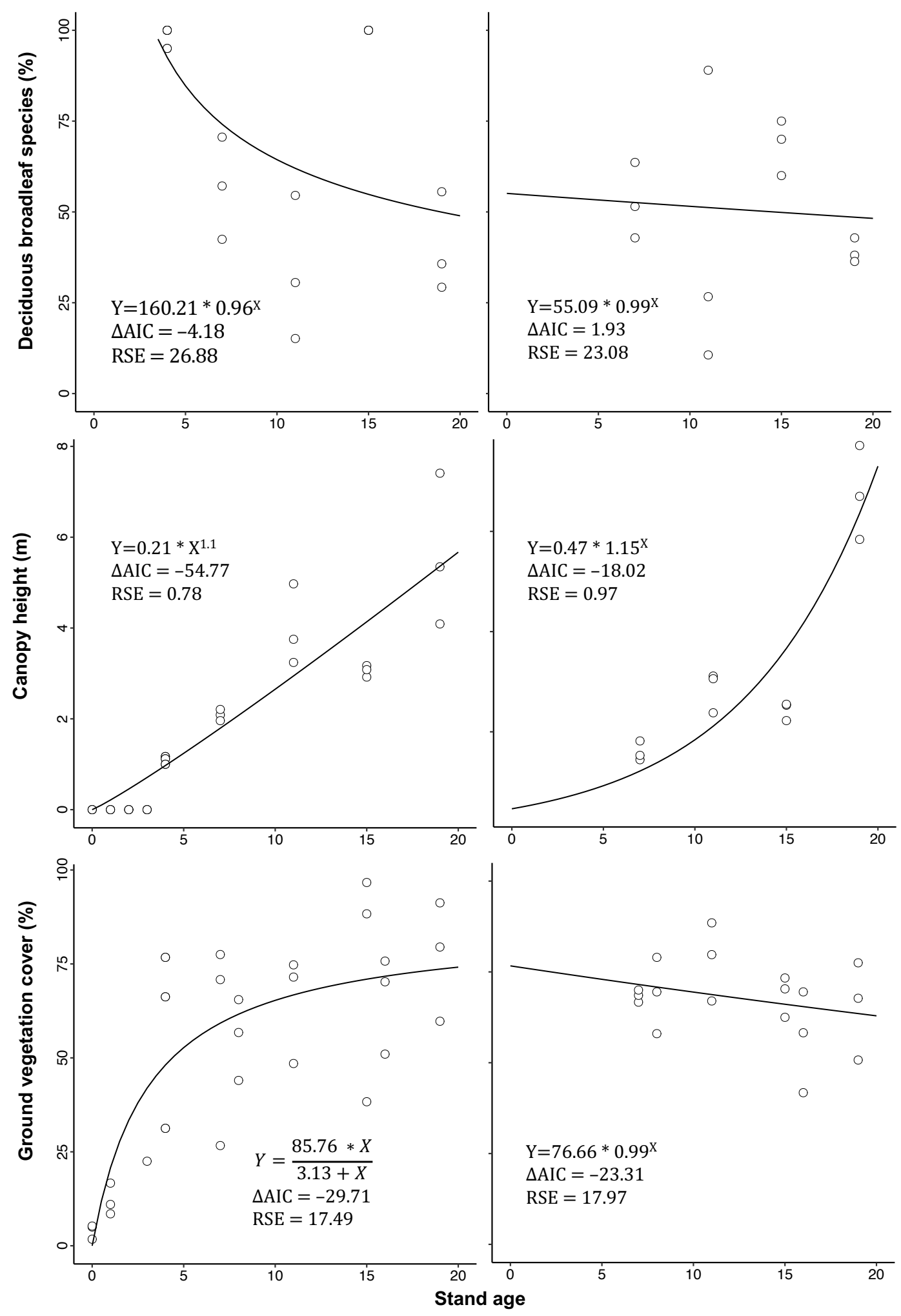

Supplementary Figure 4. Relationships between stand age and stand structural properties in the spring season. Best-fit models were chosen of the best-fit model - AIC of the corresponding null model. RSE = Residual Standard Error of the best-fit model. 

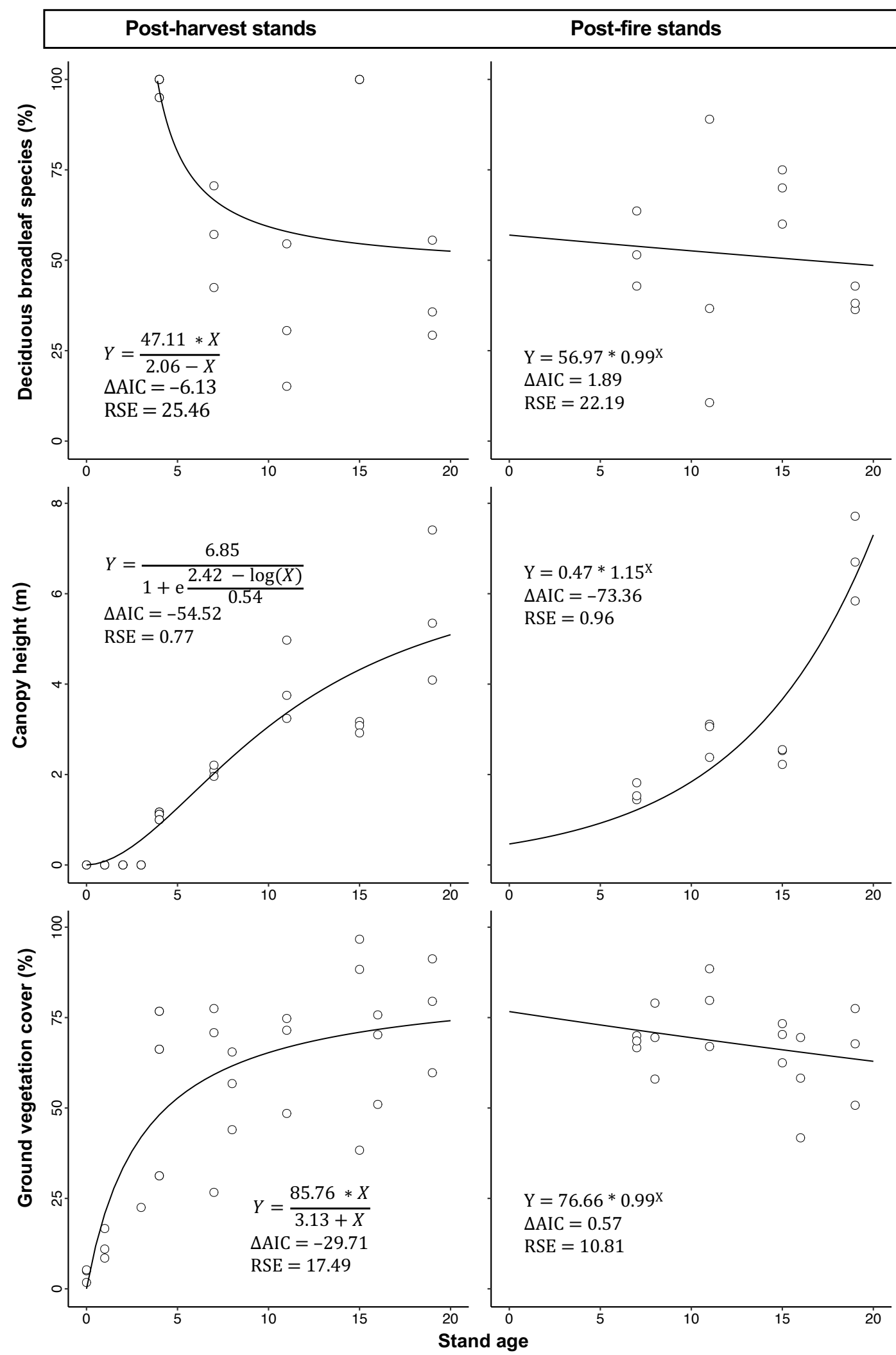

Supplementary Figure 5. Relationships between stand age and stand structural properties in the fall season. Best-fit models were chosen using an AIC-based algorithm from a set of candidate models. Estimated parameters of all models are significant at $5 \%$ level. $\Delta \mathrm{AIC}=\mathrm{AIC}$ of the best-fit model - AIC of the corresponding null model. RSE = Residual Standard Error of the best-fit model. 